Revista da Seção Judiciária do Rio de Janeiro

ARTIGOS |

DOI: https://doi.org/10.30749/2177-8337.v23n45p77-97

\title{
POLÍTICAS PÚBLICAS DE MOBILIDADE URBANA PARA PESSOAS COM DEFICIÊNCIA
}

\section{URBAN MOBILITY PUBLIC POLITICS FOR DISABLED PEOPLE}

\author{
André Machado Barbosa* \\ Eduardo Henrique Monzatto de Mattos** \\ Kátia Eliane Santos Avelar***
}

Resumo: Este artigo tem como objetivo refletir sobre a questão da acessibilidade urbana na cidade do Rio de Janeiro, sobretudo para pessoas com deficiência. Primeiramente, será discutido o conceito de mobilidade urbana, de acessibilidade e de desenho universal. A seguir, será feito um levantamento das políticas públicas existentes para verificar, a partir dos estudos de Henri Lefebvre (2001), se as políticas criadas atendem às demandas sociais do cidadão com deficiência. As conclusões indicam que a Politica Pública de Mobilidade Urbana (PNMU) é clara no que tange às ações que precisam ser implementadas com vistas a atender as pessoas com deficiências (PcDs). No entanto, efetivamente, os resultados esperados não foram encontrados na pesquisa bibliográfica consultada, trazendo à consciência a necessidade de uma pesquisa de campo bem direcionada, para recolher dados concisos ao alcance de estudiosos e interessados no assunto de extrema relevância. Tais considerações deixam ao leitor algumas indagações cabíveis a profundas reflexões quanto a alcunha de "Cidade Maravilhosa", atribuída à cidade do Rio de Janeiro.

Palavras-Chave: Direito. Henri Lefebvre. Desenho Universal.

Abstract: This article aims to reflect on the issue of urban accessibility in the city of Rio de Janeiro, especially for people with disabilities. First, the concept of urban mobility, accessibility and universal design will be discussed. Next, a survey of existing public policies will be carried out to verify, from the studies of Henri Lefebvre (2001), whether the policies created meet the social demands of the disabled citizen. The conclusions indicate that the Public Policy on Urban Mobility (PNMU) is clear on the actions that need to be implemented to address people with disabilities. But effectively the expected results were not found in the bibliographical research consulted, bringing to the awareness of the necessity of a well directed field research, to collect concise data within the reach of scholars and interested in the subject of extreme relevance. Such considerations leave to the reader some inquiries suitable to deep reflections as to the nickname of "Marvelous City", attributed to this

\footnotetext{
* Mestrando em Desenvolvimento Local, Centro Universitário Augusto Motta, Rio de Janeiro, RJ, Brasil, e-mail: andre.mb.adm@gmail.com.

** Mestrando em Desenvolvimento Local, Centro Universitário Augusto Motta, Rio de Janeiro, RJ, Brasil, e-mail: monzatto@hotmail.com.

*** Doutora em Ciências, Pesquisadora do Programa de Pós-graduação em Desenvolvimento Local, Centro Universitário Augusto Motta, Rio de Janeiro, RJ, e-mail: katia.avelar@gmail.com
} 
megalopolis city of Rio de Janeiro.

Keywords: Law. Henri Lefebvre. Universal Design. 


\section{INTRODUÇÃO}

Os estudos de Henri Lefebvre (2001) em "O direito à cidade" levam a refletir a respeito da lacuna social do direito aos aparelhos urbanos, sobretudo de forma análoga à questão da mobilidade urbana da pessoa com deficiência (PcD). Contudo, no que tange à acessibilidade, hoje já expressa em lei, contribui para uma pesquisa que justifica a relevância do assunto.

O objetivo é fazer um recorte acerca da problemática do direito à acessibilidade de modo geral das PcDs, enfatizando a questão do transporte público de qualidade e a demanda desse serviço. O foco está direcionado à cidade do Rio de Janeiro/RJ, em buscar resposta à questão norteadora da pesquisa que é: a "Cidade Maravilhosa" teria uma estrutura de mobilidade urbana para PcDs compatível com a alcunha recebida?

Respostas a questionamentos como esse implicam pensarmos no direito de ir e vir do cidadão que, nesta pesquisa, será abordada na óptica da lei, como também nas discussões dos autores, e que aqui destacamos Rousseau (1712-1778). 0 filósofo, há quatro séculos, defendia o direito de ir e vir para todos, sendo assim condição sine qua non à $\mathrm{PCD}$, que precisam se locomover para o emprego, ir a cursos de formação profissional e para universidades em busca de melhores oportunidades profissionais, entre ter acesso a cultura, lazer e principalmente à saúde. Uma vida digna e igualitária é indissociável ao processo de desenvolvimento humano, cabendo destacar o acesso ao lazer sendo imprescindível a todos. Contudo, a acessibilidade desses cidadãos aos edifícios e espaços públicos como museus, teatros, pontos turísticos, com ganhos de funcionalidade é garantia de melhor qualidade de vida para todos.

Está nos objetivos deste artigo verificar se as políticas públicas criadas são adequadas e suficientes, e se estão efetivamente sendo cumpridas. Igualmente, relatar se os benefícios estão sendo alcançados, considerando o recorte populacional pesquisado.

Lefebvre (2001) aponta que os aparelhos devem ser integrados à expansão das cidades. No que diz respeito a esse público-alvo, os aparelhos referidos são ferramentas que possibilitem o deslocamento ou a utilização de todo cenário urbano. 
Ao pensar em políticas públicas de mobilidade urbana, nos referimos à criação e funcionalidade dessas ferramentas, possibilitando às PCDs, de modo geral, a se livrarem das barreiras físicas. Por exemplo, a esses tipos de barreiras, destacam-se as calçadas em vias públicas, nas quais são acometidas de todo tipo de desordem pública e descumprimento da legislação.

\section{CIDADE E ACESSIBILIDADE}

O direito de ir e vir está expresso na Constituição Federal de 1988, e essa visão já era defendida por Rousseau (2013) no clássico livro "Do contrato social: princípios do direito político". Segundo ele, todos os homens nascem livres e a liberdade faz parte da natureza do homem e dos direitos inalienáveis como sendo a garantia equilibrada da igualdade e da liberdade.

A preocupação com a questão da mobilidade urbana para as PcDs, vista hoje como uma parcela considerável da população, clama por uma constante análise. Considerando o espaço geográfico pesquisado, o fato de que o Rio de Janeiro possui destaque mundial como uma metrópole turística, e em 1\%/07/2012 passou a ser a primeira área urbana no mundo a ter reconhecido o valor universal da sua paisagem urbana.

Irving e outros autores. (2012) informam que, além de inúmeras belezas naturais, o Rio de Janeiro contém em seu mobiliário urbano o Cristo Redentor, sendo um Patrimônio da Humanidade eleito em 2007 como uma das Sete Maravilhas do Mundo Moderno pela UNESCO. Portanto, um compromisso não apenas com as PcDs locais, como também pelo viés de cidade turística de relevante impacto.

Causa perplexidade presenciar, na atualidade, por meio das mídias sociais e algumas vezes in loco, esse direito ser negado a muitos deficientes, mesmo garantido pela lei máxima. No entanto, assistimos à saga de pessoas que necessitam de mobilidade e acessibilidade aos equipamentos urbanos serem privadas de acesso.

Compreende-se a necessidade de definição dos conceitos de mobilidade urbana, acessibilidade e desenho universal. Embora os conceitos confluam, cada qual possui sua especificidade, permitindo ao leitor uma compreensão mais clara a respeito do tema tratado neste artigo. Buscamos em Pagliuca e outros autores 
(2015) uma abordagem mais precisa a respeito e destacamos: "A aceitação da sociedade e a inclusão das pessoas com deficiência é influenciada pela perspectiva de como esta é compreendida".

O anteprojeto de lei da política nacional sobre o tema definiu Mobilidade Urbana como um atributo das cidades, e se refere à facilidade de deslocamentos de pessoas e bens no espaço urbano. Tais deslocamentos são feitos através de veículos, vias e toda a infraestrutura (vias, calçadas, etc.) que possibilitam esse ir e vir cotidiano. Nessa linha de raciocínio destacamos:

Inicialmente a análise da mobilidade urbana contemplava essencialmente questões da malha viária e da condição e fluxo de transporte de passageiros. Posteriormente, o conceito se ampliou envolvendo aspectos socioeconômicos relativos ao modo de vida nas cidades, ligando as oportunidades geradas pelo acesso aos meios de transportes para o trajeto casa-trabalho e aos serviços de saúde, educação, cultura e lazer. Nesse sentido, os benefícios da aglomeração urbana devem chegar a todos os cidadãos, o que significa garantir o direito de acesso à mobilidade urbana aos grupos de baixa renda. (PERO; MIHESSEN, 2013, p. 24)

Os autores supracitados abordam conceitos imprescindíveis à maior reflexão sobre o assunto. Apresentam algumas mudanças de paradigmas, dessa maneira "a acessibilidade universal [...] para o atendimento a cadeirantes e pessoas com dificuldades de locomoção, [...] associa-se à facilidade de alcançar fisicamente um determinado lugar." (PERO; MIHESSEN, 2013 p. 24). Complementando a ideia, mobilidade estaria relacionada à forma ou à maneira como o deslocamento seria realizado, avaliando os aspectos geográficos assim como os socioeconômicos. Nesse sentido afirmam que a mobilidade urbana é um direito social que possibilita á população participar efetivamente do desenvolvimento local em que estão inseridos.

Rubim e Leitão (2013), em "O plano de mobilidade urbana e o futuro das cidades", denotam sobre a construção de uma cidade diferente da que temos hoje. Destacam como devem ser mais inclusiva e socialmente justa essas construções, perpassando necessariamente na adoção de medidas complementares como a melhoria do transporte público coletivo, entre outras.

Em consonância à análise dos autores, Lefebvre (2001), cujo texto inspirou esta reflexiva pesquisa no capítulo que dá título ao livro "O direito à cidade", ao 
abordar sobre a ciência analítica da cidade, diz:

Uma ciência analítica da cidade, necessária, está hoje ainda em esboço. Conceitos e teorias, no começo de sua elaboração, só podem avançar com a realidade urbana em formação, com a práxis (prática social) da sociedade urbana. Atualmente a superação das ideologias e das práticas que fechavam os horizontes, que eram apenas pontos de estrangulamento do saber e da ação, que marcavam um limite a ultrapassar, essa superação, como dizia, é efetuada não sem dificuldades. (LEFEBVRE, 2001, p. 106)

Ainda sobre a questão da mobilidade urbana, Pero e Mihessen (2013) corroboram informando que há um o forte fluxo de pessoas entre as outras cidades e a capital, tornando a questão da mobilidade urbana crucial para o desenvolvimento do próprio estado. No entanto, tendo como alcunha a fama de "Cidade Maravilhosa", possui enorme expressão como capital metropolitana e vitrine do Brasil para o mundo. Dito isso, os autores destacam que:

O Rio de Janeiro é a Unidade da Federação mais metropolitana do Brasil. Segundo o CENSO/IBGE de 2010, 74\% dos fluminenses (quase 12 milhões de pessoas) residem na região metropolitana do Rio de Janeiro (RMRJ), a qual possui um a taxa de urbanização de 99,5\%, desses, $55 \%$ trabalham no município do Rio de Janeiro. (PERO; MIHESSEN, 2013, p.24)

Com a questão da mobilidade urbana compreendida em sua definição e tamanha relevância diante das abordagens dos autores destacados, cabe a compreensão do termo acessibilidade. Segundo Raia Junior (2000), há quase dois séculos, precisamente em 1826, o conceito de acessibilidade já era abordado e debatido. Desde então, várias áreas do conhecimento como a biologia, as ciências humanas, a química, a medicina, etc. se utilizam do mesmo. No entanto, o termo acessibilidade tem sido amplamente empregado em grande utilidade para as atividades de planejamento urbano e de transporte, desde os complexos sistemas de transportes coletivos até as infraestruturas mais simples, como ciclovias e calçadas.

Entretanto, Pero e Mihessen (2013) destacam que essa visão evoluiu passando também a abranger de maneira mais enfática a acessibilidade universal e os meios internacionalmente difundidos para o atendimento a cadeirantes e pessoas com dificuldades de locomoção, como as rampas de acesso. Sendo assim, acessibilidade associa-se à facilidade de alcançar fisicamente um determinado lugar; 
mobilidade, à capacidade com que o deslocamento pode ser realizado, levando em conta não só aspectos geográficos como socioeconômicos.

O Estatuto da Pessoa com Deficiência em seu artigo 30, inciso II conceitua:

[...] desenho universal: concepção de produtos, ambientes, programas e serviços a serem usados por todas as pessoas, sem necessidade de adaptação ou de projeto específico, incluindo os recursos de tecnologia assistiva. (BRASIL, 2015, p. 25).

Mace, Hardi e Place (1991) denotam que desenho universal significa simplesmente projetar todos os produtos, edifícios e espaços exteriores para ser usado por todas as pessoas na maior medida possível. Os autores, na synopsis do livro "Accessible environments: toward universal design" - Ambientes Acessíveis: Em direção ao design universal destacam:

Faced with a growing population of people with disabilities and advancing years, designers are finding an increased market as well as legal pressure to produce products, buildings and exterior spaces that are accessible to everyone. (MACE; HARDI; PLACE, 1991, p. 1).

Ao pensar que as cidades devem ser construídas para atender a todos, é notório que um arquiteto tivesse um olhar diferenciado sobre a questão. Conforme Vieira Neto (2013), e principalmente o americano Ron Mace, que em 1987 usava cadeira de rodas e um respirador artificial, criador da terminologia Universal Design. Todavia, construir uma arquitetura inclusiva é a forma de construção que respeita todas as pessoas e suas necessidades físicas. Associada com o desenho universal ou desenho para todos, vem desmistificar o "homem padrão". (VIEIRA NETO, 2013, p. 107).

Tais iniciativas geraram ideias e discussões a respeito do assunto, dando origem a leis no âmbito nacional, necessitando serem implantadas e fiscalizadas, a fim de satisfazer as necessidades do público-alvo, em especial as PcDs, que são as maiores prejudicadas. E Amartya Sen, em sua obra "Desenvolvimento como liberdade", ao final do capítulo cinco, em suas observações finais, ressalta sobre a necessidade de iniciativas da política pública na criação de oportunidades sociais em países hoje considerados periféricos, ter uma importância crucial (SEN, 2010). Ao encontro da tal observação, no tópico a seguir buscamos destacar essas politicas no 
âmbito nacional e regional demarcado nesse artigo.

A essas necessidades antropológicas socialmente elaboradas acrescentam-se necessidades específicas [...] Trata-se da necessidade de uma atividade criadora de obra (e não apenas de produtos e de bens de materiais consumíveis), necessidades de informação, de simbolismo, de imaginação, de atividades lúdicas. (LEFEBRVE, 2001, p. 105)

"O direito à cidade", livro escrito por Henri Lefebvre, corroborado por outros autores que compartilham desta visão, se confunde em particular com o direito à vida, e assim, independe do reconhecimento como membro natural ou não de algum espaço. Lefebvre clama a integralidade da cidadania a todos os membros de uma cidade, seja a qual for sendo reconhecido formalmente ou não.

\section{A POLÍTICA NACIONAL DE MOBILIDADE URBANA}

Para que a democracia seja consumada na sociedade, é indispensável que a lei regule o direito garantido. 0 "direito de ir e vir", previsto no artigo $5^{\circ}$ e seu inciso XV da Constituição Federal de 1988, informa que "é livre a locomoção no território nacional em tempo de paz, podendo qualquer pessoa, nos termos da lei, nele entrar, permanecer ou dele sair com seus bens", o que expressaria uma real democracia (BRASIL, [2016]). No entanto, a Política Nacional de Mobilidade Urbana, em seu Art. $1^{\circ}$, descreve o instrumento da política de desenvolvimento urbano de que tratam o inciso XX do Art. 21 e o Art. 182 da Constituição Federal, tendo como objetivo integrar de integrar os modais de transportes existentes primando a melhoria da acessibilidade e mobilidade das pessoas e cargas no território do Município (BRASIL, 2013).

Contudo, De Carvalho (2016, p. 7) destaca:

[...] os governantes vêm sendo bastante cobrados pela população no sentido de adotar políticas públicas efetivas que promovam a melhoria das condições de mobilidade das pessoas e a redução dos custos dos deslocamentos urbanos, principalmente os deslocamentos que utilizam transporte público coletivo.

O Ministério das Cidades, em 2013, publicou em cartilha que a mobilidade 
urbana é uma das prioridades da pauta de planejamento das cidades modernas, referindo-se à Lei no 12.587/12 (BRASIL, 2012), conhecida como Lei da Mobilidade Urbana, o que nos remete a uma profunda reflexão após cinco anos da publicação, e seis da referida lei em vigor: a sociedade e, principalmente as PcDs, sofrem pelo descumprimento da lei, e por falta de aplicabilidade de ações efetivas que garantam a uma significativa parcela desse público, o direito garantido em clausula pétrea na Constituição Federal.

Cabe destacar a visão de Faleiros (1996), em seu livro "O que é política social", no capítulo intitulado "As políticas sociais dos países periféricos", o autor descreve que nos países pobres periféricos não existe o welfare state (estado de bem-estar) tampouco um pleno keynesianismo em política. Devido à profunda desigualdade de classes, as políticas sociais não são de acesso universal, decorrentes do fato da residência do país ou da cidadania (FALEIROS, 1996, p. 28).

Sen (2010) contribui, quando aborda sobre o tema, ao dizer "bem-estar, liberdade e capacidade" destaca que muitas finalidades avaliativas, o "espaço" apropriado não é o das utilidades (como querem os "welfaristas"). As percepções de Faleiros e Sen remetem a reflexões de Lefebvre (2010) a respeito da sobre utopia experimental, devido às dificuldades encontradas pelas PcDs. Conceito esse que também intrigou a pesquisa para a escrita deste artigo, quando destaca sobre a existência de várias utopias, inclusive os prospectivistas, os planificadores que projetaram a Paris do ano 2000, e os engenheiros que fabricaram Brasília, e assim por diante. (LEFEBVRE, 2010, p.110).

Feijó e Brito (2015), ao abordarem sobre a questão da mobilidade urbana para as PcDs, denotam que a questão é uma tarefa espessa e instigante, não só por causa da dificuldade de referencial teórico sobre o assunto, mas também pela sua interdisciplinaridade (engenharia, arquitetura, finanças públicas, ciências sociais, saúde, etc.). Os mesmos autores, ao descreverem sobre planejamento urbano e a acessibilidade, ressaltam a satisfação deles ao investigarem um campo de estudo em construção, posto que ainda há muito a se conhecer e a efetivar sobre os direitos desse segmento da sociedade.

Lefebvre (2001), ao abordar o conceito de utopia experimental, adverte sobre a importância da investigação do campo de ação para o cumprimento desse 
direito, colaborando com Feijó e Brito (2015) a respeito da necessidade de investigação. Falar em planejamento requer conhecer a necessidade do público alvo e a demanda por esses direitos, e em sua obra destaca:

A utopia deve ser considerada experimentalmente, estudando-se na prática suas implicações e consequências. Estas podem surpreender. Quais são, quais serão os locais que socialmente terão sucesso? Como detectá-los? Segundo que critérios? Quais tempos, quais ritmos de vida cotidiana se inscrevem, se escrevem, se prescrevem nesses espaços "bem sucedidos", isto é, nesses espaços favoráveis à felicidade? É isso que interessa. (LEFEBVRE, 2001, p. 110)

Ao que parece, a Política Nacional de Mobilidade Urbana, desenvolvida pelo Ministério das Cidades em 2013, teve essa percepção, pois em sua cartilha informa "a base de uma política urbana com participação popular está no reconhecimento de que a participação nas políticas públicas é um direito dos cidadãos" e ressalta "que a participação da sociedade não deve ocorrer apenas no final do processo, mas em todas as etapas do planejamento das políticas públicas, inclusive nas fases iniciais de identificação das necessidades dos cidadãos" (BRASIL, 2013, p. 13-14).

Em consonância com a Política Nacional de Mobilidade Urbana, pode-se verificar que a legislação está abastada, cabendo citar: Estatuto da Pessoa com deficiência - Lei no 13.146/2015; Lei no 7.853/89; Decreto no 3.298/99; Lei no 11.126/2005; Lei no 8.160/91; Lei no 10.048/2000; Lei no 10.098/2000 e Decreto no 52.96/2004. Segundo Henriches (2017) contando também com a Lei 11.904, de 14/01/2009, que cria o Estatuto Brasileiro de Museus, no qual o tema da Acessibilidade é contemplado, a partir do qual o Instituto Brasileiro de Museus (IBRAM) editou um caderno museológico sobre acessibilidade em 2012 (HENRICHES, 2017, p. 6).

Todavia, Pagliuca e outros autores (2015) corroboram ao informar em "Repercussão de políticas públicas inclusivas segundo análise das pessoas com deficiência" que embora diversos países estejam empenhados em fazer valer os direitos das PcDs enunciados por essa Convenção, ainda persistem controvérsias e lacunas no concernente às demandas das PCDs (PAGLIUCA et al, 2015, p. 501). E, tratando da delimitação do objeto da pesquisa, em toda a bibliografia pesquisada, 0 que se pode citar, segundo Pero e Mihessen (2013), é apenas sobre a questão da mobilidade de modo geral e não específico, ao ressaltarem que ao compararmos o 
Rio de Janeiro entre as capitais nas regiões metropolitanas consideradas na pesquisa deles, estas São Paulo e Curitiba, a cidade com a alcunha de "Cidade Maravilhosa" é a campeã no tempo de deslocamento de casa ao trabalho: $28,6 \%$ gastam mais de 60 minutos no transporte (PERO, MIHESSEN, 2013, p. 30).

Entretanto, a Política Nacional de Mobilidade Urbana compõe medidas importantes a serem tratadas sobre o aspecto da acessibilidade face a todos os tipos de deficiência. Sendo assim, o tópico a seguir tratará da questão do acesso as PcDs, considerando que acessibilidade é inclusão social. Na compreensão que todas as possibilidades para o deslocamento ou a utilização de alguns espaços públicos e privados de qualquer natureza compõem a mobilidade urbana.

\section{DECRETO NO 5296/2004 - ACESSIBILIDADE}

Nosso país possui uma das melhores legislações do mundo no que diz respeito ao amparo e apoio à pessoa com deficiência $(P C D)$ conforme se constata e "tida como uma das mais avançadas do mundo" (FONSECA, 2012, p. 52). Por isso, urge a necessidade de fomentar na sociedade o maior conhecimento sobre o direito e serviços voltados às PcDs e seus familiares, assim como cobrar uma fiscalização adequada das instituições responsáveis, em todas as esferas públicas.

Ressaltamos que Decreto no 5.296 (BRASIL, 2004) regulamentou as Leis no 10.048/2000 e 10.098/2000, dando prioridade e estabelecendo normas e critérios que possibilitem promoção a acessibilidade da pessoa com deficiência - física, auditiva, visual, mental, múltipla ou com mobilidade reduzida. Além dessas, o decreto ampara pessoas com sessenta anos (ou mais), gestantes, lactantes e pessoas com crianças de colo.

Dentre os tratamentos considerados prioritários, seguindo o viés de nossa pesquisa, destacamos, no $\S 1^{0}$ do Art. 60:

I - assentos de uso preferencial sinalizados, espaços e instalações acessíveis;

II - mobiliário de recepção e atendimento obrigatoriamente adaptado à altura e à condição física de pessoas em cadeira de rodas [...];

III - serviços de atendimento para pessoas com deficiência auditiva, prestado por intérpretes ou pessoas capacitadas em Língua Brasileira de Sinais - LIBRAS e no trato com aquelas que não se comuniquem em LIBRAS, e para pessoas surdocegas, prestado por guias-intérpretes ou pessoas 
capacitadas neste tipo de atendimento;

IV - pessoal capacitado para prestar atendimento às pessoas com deficiência visual, mental e múltipla, bem como às pessoas idosas;

V - disponibilidade de área especial para embarque e desembarque de pessoa portadora de deficiência ou com mobilidade reduzida;

VI - sinalização ambiental para orientação das pessoas referidas no art. 50;

VII - divulgação, em lugar visível, do direito de atendimento prioritário das pessoas portadoras de deficiência ou com mobilidade reduzida;

VIII - admissão de entrada e permanência de cão-guia ou cão-guia de acompanhamento junto de pessoa portadora de deficiência ou de treinador nos locais dispostos no caput do art. 50, bem como nas demais edificações de uso público e naquelas de uso coletivo, mediante apresentação da carteira de vacina atualizada do animal. (BRASIL, 2004, p. 2)

E complementa citando, detalhando condições da implementação da acessibilidade: arquitetônica e urbanística; na habitação de interesse social; aos bens culturais imóveis; aos serviços de transportes públicos e coletivo rodoviário, dentre outros (BRASIL, 2004).

A partir desse ponto, outras tentativas de adequação e melhorias para atendimento a esse público específico foram surgindo, embora muitas vezes as mesmas sofram com a burocracia ou falta de interesse das autoridades competentes. Para exemplificarmos, é possível citar o Projeto de Lei no 623/2015, da Deputada Estadual do estado do RJ de Tania Rodrigues (2015), que sugeria em sua ementa regulamentar o Decreto Federal no 5.296/2004 no âmbito do estado do Rio de Janeiro, dispondo sobre a vistoria anual dos ônibus adaptados ao transporte de passageiros com deficiência e mobilidade reduzida. Lamentavelmente, depois de mais de 2 anos de tramitação, o referido projeto foi retirado de pauta em 2017.

Com a criação da Política Nacional de Saúde da Pessoa Portadora de Deficiência, sugeriu-se uma ação de "Articulação intersetorial" (BRASIl, 2008, p. 4650) com a participação efetiva de vários ministérios, a destacar: Ministério da Educação, Ministério do Desenvolvimento Social e Combate à Fome, Ministério da Justiça, Ministérios das Cidades, Ministério dos Transportes e Ministério do Trabalho e Emprego. A finalidade seria fiscalizar, incentivar, pesquisar e buscar parcerias que possibilitem a melhoria da qualidade de vida, o tratamento digno, possibilidade de inclusão social e no mercado de trabalho, assim como questões de acessibilidade e mobilidade urbana (BRASIL, 2008).

Consolidando e reforçando todas as legislações iniciativas até aqui destacadas, o Estatuto da Pessoa com Deficiência, criado a partir da Lei no 13.146 
(BRASIL, 2015), apresentou um novo viés sobre a questão de acessibilidade, valorizando e incentivando as questões sobre o "direito à cultura, ao esporte, ao turismo e ao lazer" que usualmente não eram observados:

\begin{abstract}
Art. 42: I - a bens culturais em formato acessível;
II - a programas de televisão, cinema, teatro e outras atividades culturais e desportivas em formato acessível; e

III - a monumentos e locais de importância cultural e a espaços que ofereçam serviços ou eventos culturais e esportivos.

$\S 10$ É vedada a recusa de oferta de obra intelectual em formato acessível à pessoa com deficiência, sob qualquer argumento, inclusive sob a alegação de proteção dos direitos de propriedade intelectual.

$\S 200$ poder público deve adotar soluções destinadas à eliminação, à redução ou à superação de barreiras para a promoção do acesso a todo patrimônio cultural, observadas as normas de acessibilidade, ambientais e de proteção do patrimônio histórico e artístico nacional".

"Art. 43: [...] promover a participação da pessoa com deficiência em atividades artísticas, intelectuais, culturais, esportivas e recreativas[...].

Art. 44: nos teatros, cinemas, auditórios, estádios, ginásios de esporte, locais de espetáculos [...], serão reservados espaços livres e assentos para a pessoa com deficiência. (BRASIL, 2015, p. 10-11)
\end{abstract}

Quanto às questões de direito ao transporte e à mobilidade, o Estatuto da Pessoa com Deficiência reserva o capítulo $X$, apresentando assertivas sobre: transporte coletivo; adaptação dos transportes; procedimentos para embarque e desembarque; áreas de estacionamento; incentivo à fabricação de veículos acessíveis, dentre outras. (BRASIL, 2015).

\title{
5 RESULTADOS ENCONTRADOS
}

Segundo o Censo IBGE de 2010, no estado do Rio de Janeiro, 74\% da população fluminense (aproximadamente 12 milhões) vive na área metropolitana, sendo que $55 \%$ desses trabalham na cidade do Rio de Janeiro (IBGE, 2010).

As PcDs representam 45 milhões de brasileiros, segundo o Censo/2010, o que significaria aproximadamente 1,5 milhão para o estado do Rio de Janeiro. "No caso do território objeto central de nossa análise, o município do Rio de Janeiro; [...] quando restringimos a população de 25 anos ou mais escolhida para análise de autonomia trabalhista [...]. A última proporção sobe para 33,08\%". (NERI, 2017).

Para Neri, esse aumento percentual, tanto no Rio de Janeiro como nacionalmente, se deve ao envelhecimento da população que trazem consigo 
algumas limitações nas capacidades físicas dos indivíduos. Outro aspecto comentado seria a questão da migração - "um alto padrão de mobilidade espacial das PcDs que é consistente com a busca de melhores condições de acessibilidade e cuidados". Constatou-se que 75\% afirmaram não ter nascido no Rio de Janeiro, ou seja, 3 em cada 4 entrevistados. (NERI, 2017).

Por se tratar de uma grande vitrine nacional e mundial, por seus encantos naturais e pela perspectiva de dos grandes eventos que sediou - Copa das Confederações em 2013, Copa do Mundo em 2014 e Olimpíadas/Paraolimpíadas em 2016, mereceu atenção especial para o planejamento de intervenções urbanísticas e em especial, para área de transportes (PERO E MIHESSEN, 2013).

O Decreto n 3.298/1.999 implementou a Política Pública para Integração da Pessoa Portadora de Deficiência (BRASIL,2008), expressão em desuso, assegurando os plenos direitos sociais à $\mathrm{PCD}$, inclusive no que tange aos direitos trabalhistas. O Ministério Público expede ofícios para empresas com o intuito de verificar se as cotas destinadas à PCD são efetivamente ocupadas. Ressalta que a Lei de Cotas (BRASIL, 1991) não previu multas às empresas que descumprisse a quota (NERI, 2017, p. 58).

No Rio de Janeiro, no sentido de estimular o tratamento mais adequado, assegura a partir da Lei Orgânica do Município do Rio de Janeiro, a redução de 50\% da carga horária de servidor público que seja responsável legal por PcD. Quanto às pessoas jurídicas, concede prazo especial para recolhimento de ICMS - como forma de incentivo fiscal, para a criação de vagas extras para PcD.

Apesar disso, a forma da ocupação dos espaços e a (des)organização desses espaços (grifo nosso) são fatores que dificultam o modo de vida das classes mais humildes, que moram mais afastadas da área urbana central.

De acordo com Bonfim (2010), algumas políticas implantadas em transportes urbanos nos últimos anos, tais como a implantação do Bilhete Único e a expansão da malha cicloviária, dentre outras ajudou um grupo mas, ainda, existe a necessidade de investigar mais a fundo o assunto, tendo em vista sua relevância para, nesse sentido, perceber os anseios e necessidades das classes mais pobres e que realmente necessitam de uma cidade mais funcional.

As pessoas da classe popular ou das camadas mais desfavorecidas 
economicamente constatam a privação dos direitos a ter direito à mobilidade, à acessibilidade - quando mais humilde, é um grande complicador no sentido de poder usufruir de serviços públicos de transporte e acessibilidade urbana, olhemos para um grupo que precisa de atenção específica, tendo em vista suas características especiais, as pessoas com deficiência.

Observando-se as principais dificuldades apontadas para atender esse público, ressalta-se que, além de transportes adequados às suas necessidades, com rampas, elevadores, material de sinalização e advertência, dentre outros aspectos, ainda surgem problemas de escassez do transporte em si e o devido treinamento e qualificação de seus operadores.

A qualidade dos transportes e a falta de planejamento adequado para a mobilidade urbana já motivou as manifestações populares ocorridas em 2013. Gomide e Galindo (2013 apud BARBOSA, 2015) comentam que, a partir dessas manifestações, as agendas públicas voltaram à tona, aproveitando o impacto midiático do momento. Destarte as PcDs aproveitaram a oportunidade, embora com menos visibilidade, para levantar seus anseios quanto as questões de acessibilidade e mobilidade que tanto Ihe afligem.

O problema é agravado por diversas questões arquitetônicas negligenciadas ou até mesmo não planejadas:

[...] ruas apertadas, calçadas cheias de obstáculos e que não comportam um cadeirante, transporte como barreira à locomoção, [...] problemas nas calçadas: calçada malconservada, com buracos, com entulho, inacabada ou inexistência de calçada; falha na construção de rampas rebaixadas nas calçadas; rampas obstruídas por postes, buracos (BARBOSA, 2015, p.5).

O estigma do preconceito parece superado, mas ele está evidenciado na falta de um planejamento urbano adequado. Quando uma PcD se depara com um obstáculo que o incapacita de transladar pela cidade, por uma rua, constata total privação de seu direito. Logo, é a constatação da exclusão ou de uma "inclusão pela metade", parte de uma cidadania que o reconhece pela metade.

Pinto e Ribeiro (2017) afirmam ser uma questão de cidadania o pleno reconhecimento do direito à mobilidade urbana das pessoas usualmente excluídas PcDs ou pessoas com mobilidade reduzida ou usuários vulneráveis. Comentam ainda outro aspecto importante: a necessidade de ajustar os espaços urbanos para os 
deslocamentos dos diversos agentes (carros, pedestres, ciclistas, motociclistas, cadeirantes, etc.), de maneira que se adeque os ritmos e velocidades aos locais específicos. Essa medida precisa de uma maior educação as normas de trânsito e a apropriação desses novos conceitos pelos cidadãos.

Quando a atenção se volta para o município do Rio de Janeiro, encontramos grandes dificuldades pelas PcDs, em especial as cadeirantes, quanto à possibilidade de deslocamento e acesso a espaços públicos. "O que se mostra mais premente fruto das condições adversas de acessibilidade para este grupo, [...] só em 6,9\% deles há rampa para cadeirante, sendo que $23,6 \%$ nem calçada existem", segundo fonte do IBGE 2010 (PEREIRA et al., 2018).

No que diz respeito às questões sobre o perfil socioeconômico, e ofertas no mercado de trabalho, percebemos que o segmento feminino é desprivilegiado:

2.307.621 da população com deficiência física motora são mulheres contra 1.409.612 de homens. [...] Mesmo no Brasil essa característica pode ser percebida ao mostrar que dentro do grupo das PcDM 39,3\% dos homens ocupam postos de trabalho, ao passo que o percentual de mulheres é de 25,2\%. Em termos amostrais, trabalhos como os de Christie et al. (2017) e Peccini e Giuliani (2015) mostram que uma predominância masculina em estudos com PcD pode ser um padrão. (PEREIRA et al., 2018, p. 76)

De Carvalho (2015), segundo a óptica do desenho universal, apresenta os principais desafios existentes para o avanço das políticas para a melhoria da acessibilidade nos sistemas de transporte do país, a fim de atender as pessoas com dificuldade de locomoção, permitindo exercerem livremente 0 seu direito constitucional de ir e vir.

Apesar da alta incidência de pessoas com dificuldades de locomoção, os sistemas de transporte público nunca estiveram preparados para atender adequadamente a esse segmento social. A infraestrutura urbana e de transportes, na maior parte das vezes, não foi planejada com elementos que facilitassem o deslocamento das pessoas com mobilidade reduzida. Os passeios públicos, acessos a terminais, pontos de parada e rodoviárias, entre outros, sempre foram construídos para atender pessoas adultas, dentro de um determinado padrão médio da população, sem qualquer dificuldade de locomoção; [...] observava-se na frota de transporte público coletivo a utilização de veículos originários de projetos de chassis de caminhões, com um desnível muito grande entre o piso do veículo e o das áreas de embarque, que, para ser vencido, dispunham de escadas bastante desconfortáveis para o grupo de pessoas com dificuldades de locomoção. Além disso, os sistemas de informações dos serviços de transporte urbano, 
quando existentes em um nível mínimo de caracterização, eram todos voltados exclusivamente para pessoas sem problemas sensoriais e com um nível de alfabetização elevado. Aos poucos isso vem sendo modificado no Brasil, pelo menos no seu arcabouço legal. (DE CARVALHO, 2015, p. 8)

As cidades, contemporizadas pela globalização, necessitam ir ao encontro de soluções definitivas para inserir equipamentos e mecanismos de acessibilidade, a considerar o quantitativo elevado de pessoas com deficiências que ocupam estes espaços. Nesse sentido, se faz necessário a mobilização de um esforço político, social e de profissionais engajados a esta questão para atenuar conflitos socioambientais e culturais, provenientes da massificação da urbanização.

\section{CONSIDERAÇÕES FINAIS}

$\mathrm{Na}$ bibliografia encontrada para o desenvolvimento deste artigo, compreendida a visão de Henri Lefebvre na sua obra "O direito à cidade", a importância da ciência analítica da cidade, confluindo com Amartya Sen no conceito de desenvolvimento como liberdade. E quanto à utopia experimental, nos levou entender a mensagem de Thomas More (1966), em seu livro "Utopia (1516)", porque tanto a lei quanto as políticas públicas existem, mas ainda muito distante de atender a necessidade do público alvo que consideramos nessa pesquisa, contudo, é preciso acreditar!

A respeito de mobilidade urbana, a bibliografia é ampla, mas não específica ao público para o qual a pesquisa direcionou e tampouco o território delimitado. Não houve subsídios consistentes sobre os resultados objetivados a respeito dos transportes coletivos no município do Rio de Janeiro, já estarem adaptados as PcDs. Atestamos, então, o enorme campo a uma pesquisa qualitativa, quantitativa in loco com o tema em questão, propensa a encontrar resultados para base de ações concretas direcionadas a essa massa populacional crescente em nosso munícipio.

Por exemplo, cabe destacar as pessoas com deficiência visual, ressaltando que o sistema de sinalização - tátil e/ou sonoro - não estão adequados, e em diversos locais nem são encontrados, apesar de estarem garantidos pela PNMB, por meio das leis e decretos informados. Todavia, a conscientização da população, de modo geral, tende aos comportamentos inadequados, que só fazem agravar esses 
problemas, porque ocupam os espaços apropriados para atender à necessidade das PcDs quando bloqueiam espaços de acessibilidade, conforme citado no referencial teórico da pesquisa. Normalmente, os usuários ocupam os espaços e locais reservados às PcDs de todos os tipos de deficiência, sejam nos transportes públicos, nos estacionamentos de shopping e repartições públicas e privadas, além do desrespeito e reclamações durante o embarque e desembarque, por conta de um maior tempo de parada.

Assim ficam algumas indagações para a reflexão:

a) O quanto há de se adequar os espaços garantidos pelas políticas públicas de mobilidade urbana e acessibilidade na cidade do Rio de Janeiro, visando atender dignamente as pessoas com deficiência?

b) Será que, enquanto cidadãos e pesquisadores, a sociedade atua de forma adequada fomentando e estimulando o respeito a esse público, que apesar do discurso moralmente correto de inclusão e participação social, ainda vive a margem de nossa sociedade como um todo?

Esta pesquisa teve como pretensão clamar por um olhar perene dos governantes e da sociedade em geral. A população está envelhecendo e deficiências também surgem com a senilidade. $\mathrm{O}$ Rio de Janeiro, por ser uma metrópole, está sujeita a um alto índice de acidentes de trânsito, como também a questão dos deficientes que surgem acometidos pela violência urbana.

Como uma metrópole que carrega a alcunha de "Cidade Maravilhosa", tendo diversos títulos, entre eles de ter Copacabana como a "princesinha do mar", cantada em verso e prosa por renomados nomes da música popular brasileira (MPB). Fica, então, o desejo do conceito de utopia de More (1966) de ser possível vislumbrar o direito de ir e vir ser garantido a todo cidadão, principalmente aos PcDs.

\section{REFERÊNCIAS}

BARBOSA, Adriana Silva. Mobilidade urbana para pessoas com deficiência no Brasil: um estudo em blogs. Revista Brasileira de Gestão Urbana, Campinas, v. 8, n. 1, p.142-154 2015.

BONFIM, Alexandre Bley R. Breves apontamentos sobre a aplicabilidade restrita do Código de Defesa do Consumidor aos contratos de transporte coletivo municipal de 
passageiros. A\&C: Revista de Direito Administrativo e Constitucional, Belo Horizonte, ano 10, n. 39, p. 163-182, 2010.

BRASIL. [Constituição (1988)]. Constituição da República Federativa do Brasil de 1988. Brasília, DF: Presidência da República, [2016]. Disponível em: http://www.planalto.gov.br/ccivil_03/Constituicao/Constituiçao.htm. Acesso em: 21 nov. 2018.

BRASIL. Decreto no 5.296 de 2 de dezembro de 2004. Regulamenta as Leis nos 10.048 , de 8 de novembro de 2000, que dá prioridade de atendimento às pessoas que especifica, e 10.098, de 19 de dezembro de 2000, que estabelece normas gerais e critérios básicos para a promoção da acessibilidade das pessoas portadoras de deficiência ou com mobilidade reduzida, e dá outras providências. Brasília, DF: Presidência da República, 2004. Disponível em:

http://www.planalto.gov.br/ccivil_03/_Ato2004-2006/2004/Decreto/D5296.htm. Acesso em: 20 nov. 2018.

BRASIL. Lei no 8.213, de 24 de julho de 1991. Dispõe sobre os Planos de Benefícios da Previdência Social e dá outras providências. Brasília, DF: Presidência da República, 1991. Disponível em:

http://www.planalto.gov.br/ccivil_03/leis//8213cons.htm. 20 nov. 2018.

BRASIL. Lei no 12.587 de 3 de janeiro de 2012. Institui as diretrizes da Política Nacional de Mobilidade Urbana; revoga dispositivos dos Decretos-Leis nos 3.326, de 3 de junho de 1941, e 5.405, de 13 de abril de 1943, da Consolidação das Leis do Trabalho (CLT), aprovada pelo Decreto-Lei no 5.452, de $1^{\circ}$ de maio de 1943 , e das Leis nos 5.917, de 10 de setembro de 1973, e 6.261, de 14 de novembro de 1975; e dá outras providências. Brasília, DF: Presidência da República, 2012. Disponível em: http://www.planalto.gov.br/ccivil_03/_Ato2011-2014/2012/Lei/L12587.htm. Acesso em: 20 nov. 2018.

BRASIL. Lei no 13.146 de 6 julho de 2015. Institui a Lei Brasileira de Inclusão da Pessoa com Deficiência (Estatuto da Pessoa com Deficiência). Brasília, DF:

Presidência da República, 2015. Disponível em:

http://www.planalto.gov.br/ccivil_03/_ato2015-2018/2015/lei/l13146.htm. Acesso em: 20 nov. 2018.

BRASIL. Ministério das Cidades. Secretaria Nacional de Transporte e Mobilidade Urbana. Política Nacional de Mobilidade Urbana. Brasília, DF: Ministério das Cidades, 2013.

BRASIL. Ministério da Saúde. Secretaria de Atenção à Saúde. Departamento de Ações Programáticas Estratégicas. Política Nacional de Saúde da Pessoa Portadora de Deficiência. Brasília, DF: Ministério da Saúde, 2008.

BRASIL. Senado Federal. Estatuto da pessoa com deficiência. Brasília, DF: Coordenação de Edições Técnicas; Secretaria de Editoração e Publicações, 2015. 
DE CARVALHO, Carlos Henrique Ribeiro. Desafios da mobilidade urbana no

Brasil. Brasília, DF: Instituto de Pesquisa Econômica Aplicada; Ministério do Planejamento, Orçamento e Gestão, 2016. Texto para discussão 2198.

DE CARVALHO, Carlos Henrique Ribeiro. Políticas de Melhoria das Condições de Acessibilidade do Transporte Urbano no Brasil. Texto para Discussão. Brasília, DF: Instituto de Pesquisa Econômica Aplicada; Ministério do Planejamento, Orçamento e Gestão IPEA, 2015.

FALEIROS, Vicente de Paula. O que é política social. São Paulo: Brasiliense, 1996.

FEIJÓ, Alexsandro Rahbani Aragão; BRITO, Viviane Gomes de. Planejamento urbano e a acessibilidade: o direito a uma cidade inclusiva. Revista do CEDS, São Luís, MA, n. 2, v. 1, mar./jul. 2015. Disponível em: http://www.undb.edu.br/ceds/revistadoceds. Acesso em: 09 dez. 2018.

FONSECA, Ricardo Tadeu Marques. O novo conceito constitucional de pessoa com deficiência: um ato de coragem. Revista do TRT da $2^{\mathbf{a}}$ Região, São Paulo. n. 10, p. 37-77, 2012.

HENRICHES, Maria de Fátima Lemos. Acessibilidade e museus: proposta para o projeto de pesquisa. Rio de Janeiro: Fundação Oswaldo Cruz, 2017. Curso de Especialização em Informação Científica e Tecnológica em Saúde. Disponível em: https://www.arca.fiocruz.br/bitstream/icict/29824/2/maria_henriches_icict_espec_20 18.pdf. Acesso em 08 dez. 2018.

IBGE. Censo Demográfico 2010: características gerais da população, religião e pessoas com deficiência. Rio de Janeiro:IBGE, 2010.

IRVING, Marta de Azevedo et al. Corcovado: reflexões sobre imaginários e impressões dos turistas no Parque Nacional da Tijuca (RJ) no contexto de valorização da cidade pela UNESCO. Revista Brasileira de Ecoturismo, São Paulo. v. 5, n. 3, p. 464-481, set./dez. 2012.

LEFEBVRE, Henri. $O$ direito à cidade. Tradução: Rubens Eduardo Frias. Centauro: São Paulo, 2001.

MACE, Ronald L.; HARDIE, Graeme J.; PLACE, Jaine P. Accessible environments: toward universal design. Nova York: Van Nostrand Reinhold, 1991.

MORE, Thomas. Utopia (1516). Leeds: Scolar Press Ltd., 1966.

NERI, Marcelo Cortes. Cotas empregatícias, paralimpíadas e diversidade na inclusão das pessoas com deficiência na cidade do Rio de Janeiro. Inclusão Social, Brasília, DF. v. 10, n. 2, p. 55-76, jan./jun. 2017. Disponível em:

http://revista.ibict.br/inclusao/article/view/4032/3368. Acesso em 06 dez. 2018.

VIEIRA NETO, Zanoni Vieira. Análise inclusiva nas instituições de longa permanência 
em Recife- PE. Revista de Arquitetura e Urbanismo, Recife, v. 3, n. 4, p. 104130, 2013.

PAGLIUCA, Lorita Marlena Freitag et al. Repercussão de políticas públicas inclusivas segundo análise das pessoas com deficiência. Escola Anna Nery Revista de Enfermagem. Rio de Janeiro: UFRJ, v. 19, n. 3, p. 498-504, jul./set. 2015.

PEREIRA, Lorena de Freitas et al. Condições de caminhabilidade de cadeirantes na Região Metropolitana do Rio de Janeiro (RMRJ). In: CONGRESSO LUSO-BRASILEIRO PARA O PLANEJAMENTO URBANO, REGIONAL, INTEGRADO E SUSTENTÁVEL, 8., 2018, Coimbra. Anais [...]. Coimbra: PLURIS, 2018. Disponível em: https://www.dec.uc.pt/pluris2018/Paper1457.pdf. Acesso em 09 dez. 2018.

PERO, Valéria; MIHESSEN, Vitor. Mobilidade urbana e pobreza no Rio de Janeiro. Revista Econômica, Rio de Janeiro, v. 15, n. 2, dez. 2013, p. 23-50. Disponível em: http://www.revistaeconomica.uff.br/index.php/revistaeconomica/article/view/71. Acesso em: 20 nov. 2018.

PINTO, Ana Marcela Ardila; RIBEIRO, Leticia Parente. Espaços públicos e mobilidade urbana: uma análise comparada dos arranjos normativos de Bogotá (Colômbia) e do Rio de Janeiro (Brasil). Cuadernos de Geografía: Revista Colombiana de Geografa, Bogotá, v. 26, n. 1, p. 171-186, 2017. Disponível em:

http://www.scielo.org.co/pdf/rcdg/v26n1/v26n1a12.pdf. Acesso em: 18 nov. 2018.

RAIA JUNIOR, Archimedes Azevedo. Acessibilidade e mobilidade na estimativa de um índice de potencial viagens utilizando redes neurais artificiais e sistemas de informações geográficas. 2000. 212f. Tese (Doutorado em Engenharia Civil) - Escola de Engenharia de São Carlos, Universidade de São Paulo. 2000. Disponível em: http://www.teses.usp.br/teses/disponiveis/18/18137/tde10112001-160812/pt-br.php. Acesso em: 02 dez. 2018.

RODRIGUES, Tania. Projeto de Lei n⿳0 623/2015. Regulamenta o decreto federal no 5296/2004 no âmbito do estado do Rio de Janeiro, dispondo sobre a vistoria anual dos ônibus adaptados ao transporte de passageiros com deficiência e mobilidade reduzida. Rio de janeiro: ALERJ, 2015. Disponível em: http://alerjln1.alerj.rj.gov.br/scpro1519.nsf/1061f759d97a6b24832566ec0018d832/d 11e56c6e9de49f083257e970056bf69?OpenDocument\&CollapseView. Acesso em: 08 dez. 2018.

ROUSSEAU, Jean-Jacques. Do contrato social: princípios do direito político. Tradução: Vicente Sabino Júnior. São Paulo: Pilares, 2013.

RUBIM, Barbara; LEITÃO, Sergio. O plano de mobilidade urbana e o futuro das cidades. Estudos avançados, São Paulo, v. 27, n. 79, p. 55-66, 2013. Disponível em: https://www.revistas.usp.br/eav/article/view/68702. Acesso em: 02 dez. 2018.

SEN, Amartya. Desenvolvimento como liberdade. Tradução: Laura Teixeira Motta. São Paulo: Companhia das Letras, 2010. 